\title{
Conforto Térmico em Corredores Urbanos: Estudo de Caso em Bauru-SP
}

\author{
Arq. Carla Cristina Amaral \\ Dra. Maria Solange Gurgel de Castro Fontes \\ Instituição: FAAC/UNESP
}

\section{Resumo}

O intenso uso de veículos motorizados nos corredores urbanos, por onde também circulam veículos não motorizados e pedestres, tem contribuído para produção de ruídos, poluição do ar e calor, que degradam o ambiente e, consequentemente, a qualidade de vida dos pedestres. Esse aspecto é agravante em áreas comerciais e de prestação de serviços, como a av. Rodrigues Alves localizada em Bauru-SP, objeto de estudo deste trabalho, que é focado no ambiente térmico do pedestre. O trabalho envolve aspectos subjetivos (questionários) e objetivos (monitoramento microclimático) na avaliação das condições de conforto térmico de pedestres. Os resultados revelam uma faixa de conforto térmico para o índice PET de 16,4 a 28 oC, evidenciando menor tolerância às altas temperaturas e maior às mais baixas, em comparação com resultados desenvolvidos em estudo similar realizado em um espaço público de permanência arborizado em Bauru.

\section{Introdução}

Os corredores urbanos como as ruas e avenidas, por onde circulam veículos motorizados ou não e pedestres, são projetados, de uma maneira geral, visando o escoamento e fluidez do trânsito, com pouco ou nenhum foco na qualidade de vida das pessoas. Assim, os pedestres ficam expostos às adversidades do clima e vários tipos de poluição (do ar, sonora e visual), causando stress daqueles que fazem uso diário desses espaços. Atualmente, o aumento da frota de veículos motorizados nas cidades e a falta de qualidade do espaço urbano têm contribuído para agravar esses problemas e, por isso, torna-se urgente a necessidade de requalificação dos espaços urbanos, com ênfase no conforto ambiental dos pedestres.

Do ponto de vista térmico, tem crescido o número de pesquisas que utilizam índices preditivos de conforto como ferramenta de análise da qualidade do espaço urbano, objetivando subsidiar projetos de requalificação urbana. No Brasil, esse crescimento pode ser visualizado nos anais do último Encontro Nacional e Latino Americano de Conforto no Ambiente Construído - ENCAC e ELACAC, através das pesquisas desenvolvidas por Fontes \& Brusantin, 2011; Hirashima et al., 2011; Rancura \& Labaki, 2011; Rossi et al., 2011; Shinyashiki \& Bueno_Bartholomei; Wolfram \& Monteiro, 2011. Algumas dessas pesquisas também foram publicadas em uma edição especial sobre "conforto ambiental e eficiência energética" da Revista online "Ambiente Construído", em jan/mar de 2012 (Labaki et al., 2012; Monteiro \& Alucci, 2012; Krüger et al., 2012; Rossi et al., 2012). 
Muitos desses estudos, desenvolvidos no Brasil e em outros países, possuem como ponto comum o trabalho de campo, através da coleta de aspectos subjetivos dos pedestres (questionários) e objetivos (monitoramento microclimático), indispensáveis à avaliação das condições de conforto térmico de pedestres e na determinação de faixas de stress térmico. Um dos índices térmicos muito utilizado nesses estudos é a Temperatura Equivalente Fisiológica - PET, desenvolvido por Mayer \& Höppe (1987), que representa a temperatura fictícia resultado da inter-relação das variáveis ambientais e físicas de um determinado ambiente real. A temperatura resultante desse processo é calculada com base em modelo de balanço energético para indivíduos de Munique (MEMI). Segundo Höppe (1993, 1999), a PET é equivalente a temperatura do ar de um determinado ambiente típico, cujo valor da temperatura radiante média é igual a temperatura do ar e a velocidade do ar é de $0,1 \mathrm{~m} / \mathrm{s}$, e a pressão de vapor d lágua é de 12 hPA. A grande aplicabilidade da PET deve-se, em parte, a facilidade de uso através do software RayMan (Matzarakis et al., 2007).

Independetemente do índice utilizado, outro ponto comum nessas pesquisas é a dificuldade na definição precisa das faixas de conforto/desconforto para cada voto de sensação real. Assim, são necessárias muitas pesquisas de campo, em diferentes condições de tempo, para a calibração dos índices de conforto. Por isso, é de fundamental importância a multiplicação de trabaIhos semelhantes, o qual se insere este trabalho que tem como objetivo estudar os microclimas e condições de conforto térmico de pedestres em um importante eixo viário: a avenida Rodrigues Alves em Bauru-SP. Essa avenida é polo de atração dos transportes públicos e se transforma em um extenso terminal urbano, na área central. Nessa área foram monitoradas as condições microclimáticas, simultaneamente a aplicação de questionários e os dados levantados permitiram compararar o conforto térmico real com o calculado e avaliar os limites de conforto/desconforto para cada voto de sensaçãotérmico real.

\section{Materiais de Métodos}

Para cumprir os objetivos da pesquisa foram realizados monitoramentos de variáveis ambientais (temperatura do ar e de globo, umidade relativa do ar, velocidade do ar e irradiação solar global) em 3 diferentes pontos da avenida, utilizando uma estação meteorológica móvel (figura 1). As medições foram efetuadas em 6 dias, 3 no mês de julho e 3 em dezembro, das 9 às $12 \mathrm{~h}$ (manhã) e das 14 às 17h (tarde), em diferentes condições de tempo. Paralelamente aos monitoramentos, foram aplicados questionários a uma amostra significativa de usuários. Também foi feita uma caracterização do tipo de uso e ocupação dos espaços e levantamentos de fotos hemisféricas para cálculo do Fator de Visão do Céu (FVC), utilizando o software RayMan (Matzarakis et al., 2007). As caracteristicas das condições climáticas, nos dias de observação de campo foram extraídos do IPMet- Instituto de Pesquisas Meteorológicas, localizado em Bauru.

Para definição do tamanho da amostra foi estimada uma faixa de usuários fixa e margem de erro em torno de $10 \%$. Assim, foi estipulada a quantidade mínima 101 usuários, em cada período do ano (julho e dezembro), totalizando 202 usuários, escolhidos de maneira aleatória. Os levantamentos de campo permitiram fazer uma caracterização dos usuários, das atividades desenvolvidas e avaliar suas condições de stress térmico em diferentes épocas do ano (julho e

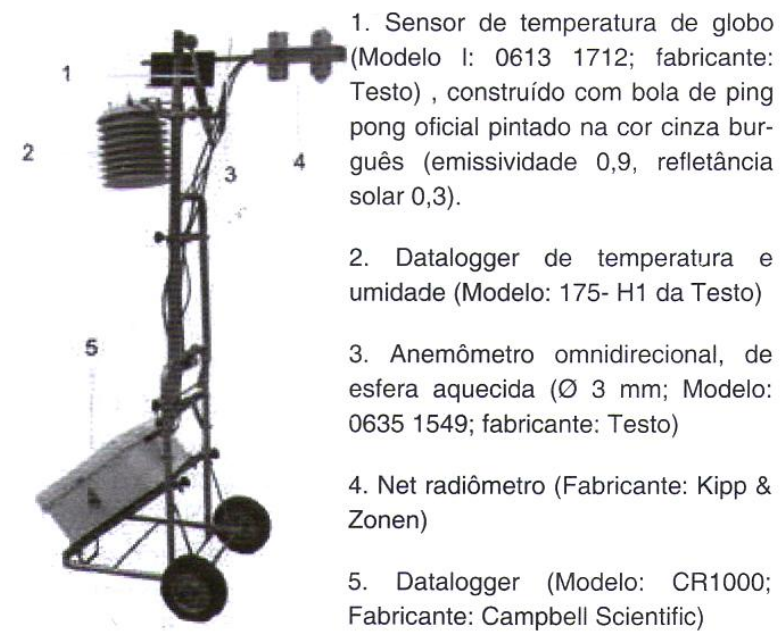

Figura 1: Estação meteorológica móvel.

dezembro), períodos do dia (manhã e tarde) e condições de tempo (quente seco, quente e úmido e frio e seco). Para a análise do conforto térmico foram considerados aspectos subjetivos (questionários), levando em conta a opinião dos usuários e dados objetivos, através do cálculo da Temperatura Equivalente Fisiológica (PET) utilizando o software RayMan. A faixa de 18-26 C foi considerada como confortável, de acordo com a proposição de Labaki et al. (2012) para cidades do interior Paulista. Ressalta-se que essa mesma faixa de conforto também foi proposta por Monteiro \& Alucci (2007) para espaços abertos da cidade de São Paulo.

Os dados levantados em campo foram tratados de duas formas: a primeira considerou as diferenças entre o conforto térmico real (sensação térmica), calculado (através do índice PET) e com a satisfação térmica (resposta entre sim ou não para a questão "você se sente confortável?"), 
nos dois períodos (julho e dezembro); a segunda levou em conta como cada valor da PET foi distribuído em função dos votos de sensação real, a partir de uma escala de valores de 7 pontos, que variou de -3 (muito frio) a 3 (muito quente).

\section{3. Área de Estudo}

A área de estudo fica localizada na avenida Ro- drigues Alves (figuras 2 e 3 ) em Bauru-SP (Lat - 220 35' e Long - 49031'), cidade de porte médio do Centro Oeste Paulista, cujo clima pertence ao tipo Aw, de acordo com a classificação climática de Koeppen para o Estado de São Paulo, considerado clima tropical chuvoso com inverno seco e mês frio com temperatura média superior a 18 ${ }^{\circ} \mathrm{C}$ (CEPAGRI, 2011).

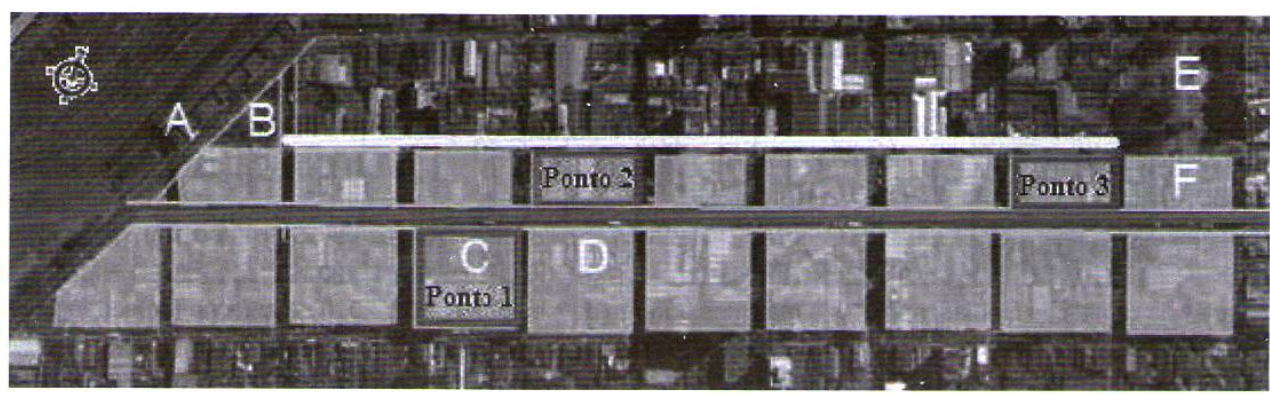

LEGENDA:

A - Estação Ferroviária; B - Praça Machado de Melo; C - Praça Dom Pedro e Câmara Municipal dos Vereadores; D - Igreja Universal do reino de Deus; E- Praça Rui Barbosa F- Catedral

Avenida Rodrigues Alves Rua de pedestres (Batista de Carvalho)

Figura 2: Vista aérea da avenida Rodrigues Alves com destaque para os pontos de medição e locais de referência

Ponto 1
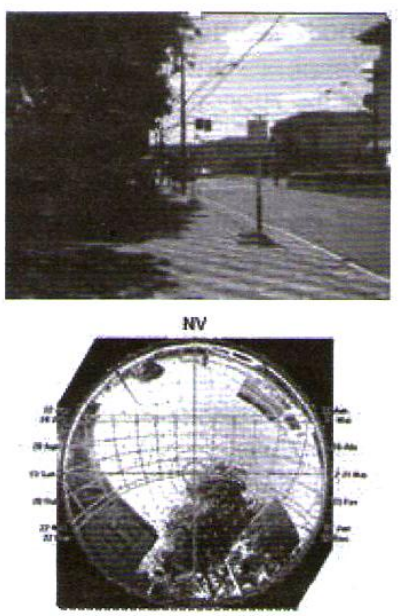

FVC $=0,435$
Ponto 2

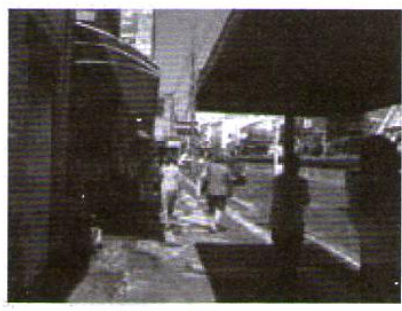

NV

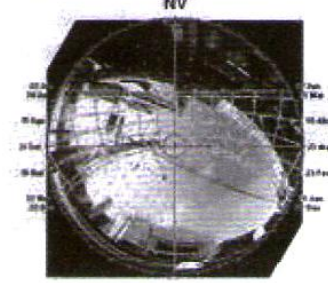

$\mathbf{F V C}=\mathbf{0 , 3 5 3}$
Ponto3

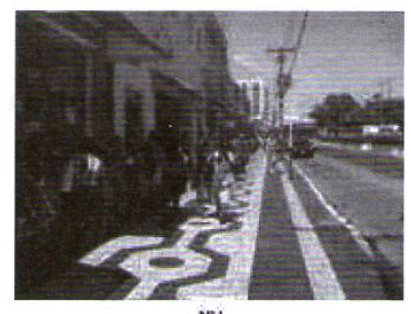

NV

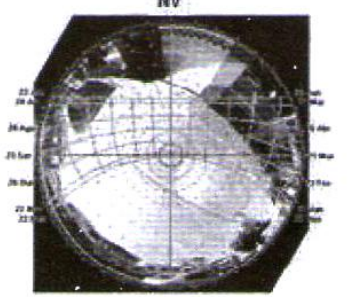

FVC $=0,394$

Figura 3: Imagens dos pontos de monitoramento de dados microclimáticos e respectivas fotografias hemisféricas com sobreposição da carta solar e indicação do Fator de Visão do Céu.

Em virtude de Bauru ser uma cidade Regional, que tem o comércio e a prestação de serviços como principais atrativos, sua área central é um polo de concentração dos transportes públicos e privados e de pessoas, especialmente nos horários comerciais. Nesse trecho foram escolhidas as quadras 4, 5 e 9 para levantamento de dados microclimáticos e aplicação dos questionários, em função da existência de pontos de ônibus urbanos e grande fluxo de pessoas. A figura 3 mostra uma imagem da área de estudo, com des- taque para os locais de medição, alguns pontos de referências, além de fotografias hemisféricas, com sobreposição da carta solar de Bauru, que ressaltam o período de insolação em cada ponto, ao longo do ano.

\section{Resultados}

A análise dos resultados é realizada, inicialmente, em cada período de monitoramento de dados. Assim, são apresentados e analisados os resultados das medições realizadas nos dias 6,7 e 8 


\begin{tabular}{|c|c|c|c|c|}
\hline \multirow[b]{2}{*}{$\begin{array}{c}\text { Dias e } \\
\text { horários }\end{array}$} & \multicolumn{4}{|c|}{ Variáveis climáticas } \\
\hline & $\begin{array}{c}\text { Temperatura } \\
\left({ }^{\circ} \mathrm{C}\right)\end{array}$ & $\begin{array}{c}\text { Umidade } \\
\text { Relativa(\%) }\end{array}$ & $\begin{array}{l}\text { Velocidade } \\
\text { do } \operatorname{ar}(\mathrm{m} / \mathrm{s})\end{array}$ & $\begin{array}{c}\text { Radiação } \\
\text { solar }(\mathbf{w} / \mathbf{m} 2)\end{array}$ \\
\hline \multirow[t]{2}{*}{$\begin{array}{c}06 / 07 / 2010 \\
9-12 \mathrm{~h}\end{array}$} & $\begin{array}{c}19,35 \\
(14,4 \text { e } 24,3) \\
\end{array}$ & $\begin{array}{c}60,5 \\
(78 \text { e } 49) *\end{array}$ & $\begin{array}{c}2,7 \\
(2,9 \text { e } 2,5)^{*}\end{array}$ & $\begin{array}{c}1654 \\
(2423 \text { e } 885)^{*}\end{array}$ \\
\hline & $\begin{array}{c}26,05 \\
(27,1 \text { e } 25)^{*}\end{array}$ & $\begin{array}{c}37 \\
(42 \text { e } 32)^{*}\end{array}$ & $\begin{array}{c}1,75 \\
(2,1 \text { e } 1,4)^{*}\end{array}$ & $\begin{array}{c}1224,5 \\
(2334 \mathrm{e} 115)^{*}\end{array}$ \\
\hline \multirow[t]{2}{*}{$\begin{array}{c}07 / 07 / 2010 \\
9-12 \mathrm{~h}\end{array}$} & $\begin{array}{c}20,75 \\
(24,5 \text { e } 17,0)^{*}\end{array}$ & $\begin{array}{c}58 \\
(73 \text { e } 43)^{*}\end{array}$ & $\begin{array}{c}2,4 \\
(2,9 \text { e } 1,9)^{*}\end{array}$ & $\begin{array}{c}1465 \\
(2055 \text { e } 875)^{*}\end{array}$ \\
\hline & $\begin{array}{c}25,8 \\
(27,2 \text { e } 24,4) *\end{array}$ & $\begin{array}{c}34,5 \\
(38 \text { e } 31)^{*}\end{array}$ & $\begin{array}{c}1,6 \\
(1,9 \mathrm{e} 1,3)^{*}\end{array}$ & $\begin{array}{c}1172 \\
(2227 \text { e } 117) *\end{array}$ \\
\hline \multirow{2}{*}{$\begin{array}{c}08 / 07 / 2010 \\
9-12 \mathrm{~h} \\
14-17 \mathrm{~h}\end{array}$} & $\begin{array}{c}19,85 \\
(16,20 \mathrm{e} 23,5)^{*}\end{array}$ & $\begin{array}{c}46,5 \\
(61 \text { e } 32)^{*}\end{array}$ & $\begin{array}{c}1,5 \\
(2 \mathrm{e} 1)^{*}\end{array}$ & $\begin{array}{c}1269 \\
(2248 \text { e } 290)^{*}\end{array}$ \\
\hline & $\begin{array}{c}24,9 \\
(26,6 \text { e } 23,2)^{*}\end{array}$ & $\begin{array}{c}36,5 \\
(45 \text { e } 28)^{*}\end{array}$ & $\begin{array}{c}1,5 \\
(2 \mathrm{e} 1) \\
\end{array}$ & $\begin{array}{c}1269 \\
(2248 \text { e } 290)^{*}\end{array}$ \\
\hline
\end{tabular}

Tabela 1: Variáveis climáticas médias, mínimas e máximas durante os dias 6, 7 e 8/07/ 2010 da estação meteorológica local Fonte - IPMet - Instituto de Pesquisas Meteorológicas da UNESP

*valores máximos e mínimos obtidos no IPMet durante os períodos da manhã e tarde nos mesmos horários da coleta de dados na avenida Rodrigues Alves.

de julho de 2010 e depois nos dias 7, 8 e 9 de dezembro do mesmo ano, além das condições do tempo. Em seguida é feita uma análise conjunta dos dois períodos. As características dos usuários entrevistados, os níveis de isolamento das roupas e as taxas metabólicas também são descritas.

\subsection{Medições 6,7 e 8 de Julho de 2010}

Durante o monitoramento de dados de julho (tabela 1), os valores da temperatura média do ar variaram de $19,4^{\circ} \mathrm{C}$ (manhã) a $25,8^{\circ} \mathrm{C}$ (tarde), caracterizando manhãs frias e tardes amenas. Já os dados de umidade relativa média oscilaram de $60,5 \%$ (manhã) a 34,5\% (tarde). Esses valores atribuíram ao local condições de tempo seco $(55 \%$ e $75 \%$ ) e muito seco (abaixo de $55 \%$ ), de acordo com a classificação geral do clima segundo Romero (1988).
Nessas condições microclimáticas, o nível de isolamento médio da roupa dos usuários foi de 0,75 clo, com valores mínimos e máximos de 0,44 e 1,12 clo, respectivamente. Outras características dos usuários entrevistados foram: taxa metabólica média de 95,3 w/m2, variando de 93 a $110 \mathrm{w} /$ $\mathrm{m} 2$; predominância de mulheres $(60 \%)$ e faixas etárias de: adolescente até 17 anos (8\%), 18-24 anos (25\%), 25-34 (22\%), 35-44 (22\%), 45-54 (11\%), 55-64 (7\%) e acima de 65 anos (5\%). Os motivos de uso do espaço foram: pegar ônibus (39\%), trabalhar no centro $(27 \%)$, entre outros (estudar, passear, fazer compras, ir a lugares específicos e alguns somente de passagem). As características dos usuários, constituídas por diferentes faixas etárias e classes econômicas, evidenciaram uma convivência democrática e grande vitalidade diária da área de estudo, durante o trabalho de campo.

Os dados coletados em campo permitiram fazer

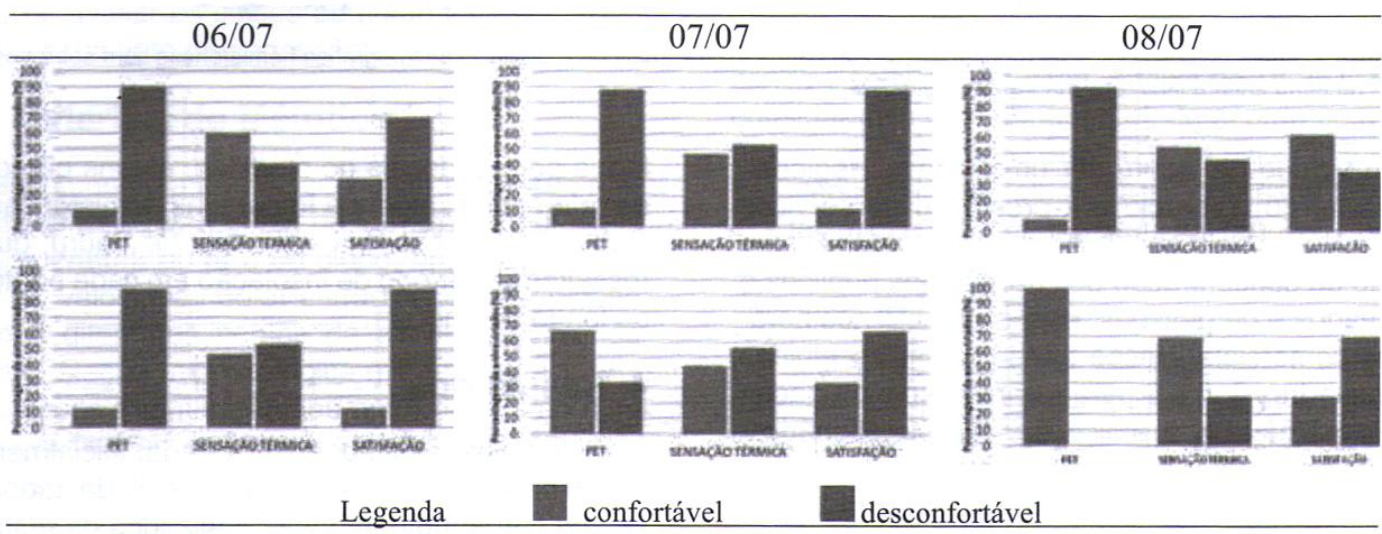

Tabela 2: Análise comparativa por períodos (manhã e tarde) entre o conforto térmico real (sensação térmica), conforto térmico calculado (PET) e satisfação térmica, nos dias 6, 7 e 8 de julho de 2010. 
uma análise comparativa entre o conforto térmico real (sensação térmica) e calculado (pelo índice PET), além da satisfação térmica, que pode ser visualizada na tabela 2. Nesse período, 58 das 101 pessoas entrevistadas disseram sentir "nem quente nem frio" para a sensação térmica, resultando numa porcentagem de $57,4 \%$ de pessoas confortáveis. Para o conforto térmico real, observou-se uma maior tendência de usuários confortáveis no período da manhã $(56,9 \%)$. De uma maneira geral a causa da insatisfação térmica no período foi o frio pela manhã e a secura do ar no período da tarde, em virtude dos baixos valores das umidades relativa do ar.

Para a análise do conforto calculado foi considerada a faixa de $18-26^{\circ} \mathrm{C}$ como confortável, de

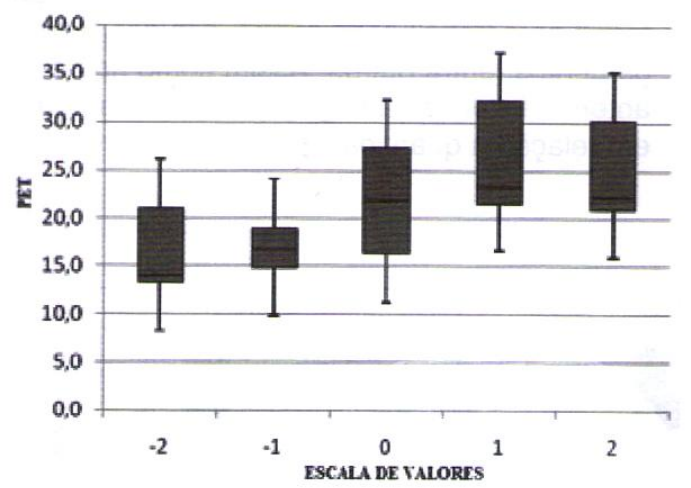

acordo com proposição de Labaki et al. (2012). Desta forma, a análise do conjunto de valores de PET ressaltou uma grande quantidade de pessoas desconfortáveis, especialmente durante o período da manhã, quando as temperaturas estavam mais baixas. Por outro lado, os votos de sensação térmica (conforto térmico real) apontaram para uma maior quantidade de pessoas confortáveis, indicando a necessidade de ajuste na faixa de conforto calculado.

Para melhor definição da faixa de conforto, necessária para avaliação da qualidade dos espaços públicos de passagem em Bauru, o conjunto de valores de PET para cada voto de sensação foi analisado através do gráfico estatístico tipo boxplot. A figura 4 mostra que os dados obtidos

\begin{tabular}{|c|c|c|c|}
\hline \multirow{2}{*}{ Escala de valores } & \multicolumn{3}{|c|}{$\begin{array}{l}\text { Faixa de PET para } 50 \% \\
\text { dos valores centrais }\left({ }^{\circ} \mathrm{C}\right)\end{array}$} \\
\hline & Mín & Med. & Máx \\
\hline Frio & 13,3 & 14,1 & 21,1 \\
\hline Pouco Frio & 14,8 & 16,7 & 19,1 \\
\hline $\begin{array}{l}\text { Nem frio nem } \\
\text { quente }\end{array}$ & 16,3 & 22,0 & 27,4 \\
\hline Pouco quente (1) & 21,6 & 23,3 & 32,3 \\
\hline Quente & 20,9 & 32,3 & 30,3 \\
\hline
\end{tabular}

Figura 4: Gráfico tipo Box plot com distribuição do conjunto de valores de PET para cada voto de sensação térmica e tabela com as medianas (med) e dos limites (mínimo e máximo) de conforto/desconforto para $50 \%$ dos valores centrais durante os dias 6,7 e $8 / 07 / 2010$

foram distribuídos entre os valores "-2, -1, 0, 1 e 2 ", que correspondem a "frio, pouco frio, nem frio nem quente, pouco quente e quente". Para esse período não foram encontrados os conjuntos de valores de " -3 e +3 ", que correspondem a "muito frio e muito quente", respectivamente.
A figura 4 mostra ainda, que as maiores dispersões dos valores estão nos conjuntos "0" e "1" e a menor no conjunto "- 1 " e que os valores das medianas tendem a ser crescentes, acompanhando a escala de valores. Para o conjunto de valores "0", a faixa de PET encontrada para $50 \%$ dos valores centrais da amostra foi de 16,3 a 27 ,

\begin{tabular}{|c|c|c|c|c|}
\hline \multirow[b]{2}{*}{$\begin{array}{c}\text { Dias e } \\
\text { horários }\end{array}$} & \multicolumn{4}{|c|}{ Variáveis climáticas } \\
\hline & $\begin{array}{c}\text { Temperatura } \\
\left({ }^{\circ} \mathrm{C}\right)\end{array}$ & $\begin{array}{c}\text { Umidade } \\
\text { Relativa }(\%)\end{array}$ & $\begin{array}{l}\text { Velocidade } \\
\text { do } \operatorname{ar}(\mathrm{m} / \mathrm{s})\end{array}$ & $\begin{array}{l}\text { Radiação solar } \\
(\mathbf{w} / \mathbf{m} 2)\end{array}$ \\
\hline $\begin{array}{r}07 / 12 / 2010 \\
9 \text { as } 12 \text { h }\end{array}$ & $\begin{array}{c}21,35 \\
(24,9 \text { e } 18)^{*}\end{array}$ & $\begin{array}{c}82,83 \\
(95 \text { e } 70)^{*}\end{array}$ & $\begin{array}{c}1,56 \\
(1,8 \text { e } 1,3)^{*}\end{array}$ & $\begin{array}{c}1387 \\
(2244 \text { e } 468,1)^{*}\end{array}$ \\
\hline 14 as $17 \mathrm{~h}$ & $\begin{array}{c}30,21 \\
(31,6 \text { e } 29)^{*} \\
\end{array}$ & $\begin{array}{c}54,83 \\
(60 \text { e } 50)^{*}\end{array}$ & $\begin{array}{c}2,26 \\
(3 \mathrm{e} 1,7)^{*}\end{array}$ & $\begin{array}{c}727 \\
(1141 \text { e } 31,7)^{*} \\
\end{array}$ \\
\hline $\begin{array}{r}\text { 08/12/2010 } \\
9 \text { as } 12 \mathrm{~h}\end{array}$ & $\begin{array}{c}21,35 \\
(24,9 \text { e } 18)^{*} \\
\end{array}$ & $\begin{array}{c}83,83 \\
(95 \text { e } 72)^{*} \\
\end{array}$ & $\begin{array}{c}2,3 \\
(4,8 \text { e } 0,3)^{*}\end{array}$ & $\begin{array}{c}727 \\
(1141 \text { e } 319,7)^{*}\end{array}$ \\
\hline 14 as $17 \mathrm{~h}$ & $\begin{array}{c}23,61 \\
(25,7 \text { e } 21,1)^{*}\end{array}$ & $\begin{array}{c}51,16 \\
(57 \text { e } 47)^{*} \\
\end{array}$ & $\begin{array}{c}3,4 \\
(4,1 \text { e } 2,5) * \\
\end{array}$ & $\begin{array}{c}3136,33 \\
(2203 \text { e } 2810)^{*} \\
\end{array}$ \\
\hline $\begin{array}{r}09 / 12 / 2010 \\
9 \text { as } 12 \mathrm{~h}\end{array}$ & $\begin{array}{c}23,16 \\
(26,5 \text { e } 19,7)^{*}\end{array}$ & $\begin{array}{c}84,33 \\
(96 \text { e } 67)^{*}\end{array}$ & $\begin{array}{c}2,26 \\
(2,8 \text { e } 1,3) *\end{array}$ & $\begin{array}{c}1319,13 \\
(2203 \text { e } 2810)^{*}\end{array}$ \\
\hline 14 as $17 \mathrm{~h}$ & $\begin{array}{c}29,41 \\
(30,7 \text { e } 28,3)^{*}\end{array}$ & $\begin{array}{c}53 \\
(59 \text { e } 47)^{*}\end{array}$ & $\begin{array}{c}2,2 \\
(2,8 \mathrm{e} 1,3) *\end{array}$ & $\begin{array}{c}2749,66 \\
(3353 \text { e } 2373)^{*}\end{array}$ \\
\hline
\end{tabular}

Tabela 3: Variáveis climáticas médias, mínimas e máximas durante os dias 7, 8 e 9/12/ 2010 da estação meteorológica local Fonte - IPMet - Instituto de Pesquisas Meteorológicas da UNESP

*valores máximos e mínimos obtidos no IPMet durante períodos da manhã e tarde nos mesmos horários da coleta de dados na avenida Rodrigues Alves. 
$4^{\circ} \mathrm{C}$ e os dados desse conjunto foram distribuídos simetricamente em torno do valor mediano de $22,0^{\circ} \mathrm{C}$.

\subsection{Medições 7,8 e 9 de Dezembro de 2010}

No período de monitoramento de dados de dezembro (tabela 3 ), os valores da temperatura média do ar variaram de $22,0^{\circ} \mathrm{C}$ (manhã) a 27,7 ${ }^{\circ} \mathrm{C}$ (tarde), caracterizando manhãs com temperaturas quentes (acima de $20^{\circ} \mathrm{C}$ ) e tardes muito quentes. Já os dados da umidade relativa média oscilaram de $83,7 \%$ (manhã) a 53,0\% (tarde), valores que atribuíram condições de tempo úmido durante as manhãs (entre 75 e $90 \%$ ) e seco (55 e $75 \%$ ) no período da tarde, segundo classificação geral do clima apresentada em Romero (1988).

Nessas condições microclimáticas, o nível de isolamento médio da roupa dos usuários foi de 0,47 clo e com valores mínimos e máximos de 0,26 e 0,73 clo, respectivamente. Em relação ao período anterior houve uma redução de 0,28 clo nos valores de isolamento médio desse nível, evidenciando as características adaptativas dos usuários às variações de tempo. Outra característica dos usuários entrevistados foi a taxa metabólica média de 96,2 w/m2, variando de 58 a $110 \mathrm{w} / \mathrm{m} 2$.

Os motivos de uso do espaço apontado pelos usuários foram os mesmos do período anterior, mas com algumas porcentagens diferenciadas. Em virtude do mês de dezembro ter incremento nas compras para o Natal, foi verificado um aumento da porcentagem de pessoas que, após fazer compras, foram esperar ônibus na avenida, ou apenas passaram na avenida para esse fim. Juntas essas pessoas representaram $62 \%$ do total dos entrevistados. Demais porcentagens foram para trabalhar no centro, estudar, fazer pagamentos, entre outras. Assim como no período anterior, foi observado grande vitalidade no local, em relação a quantidade de pessoas presentes.

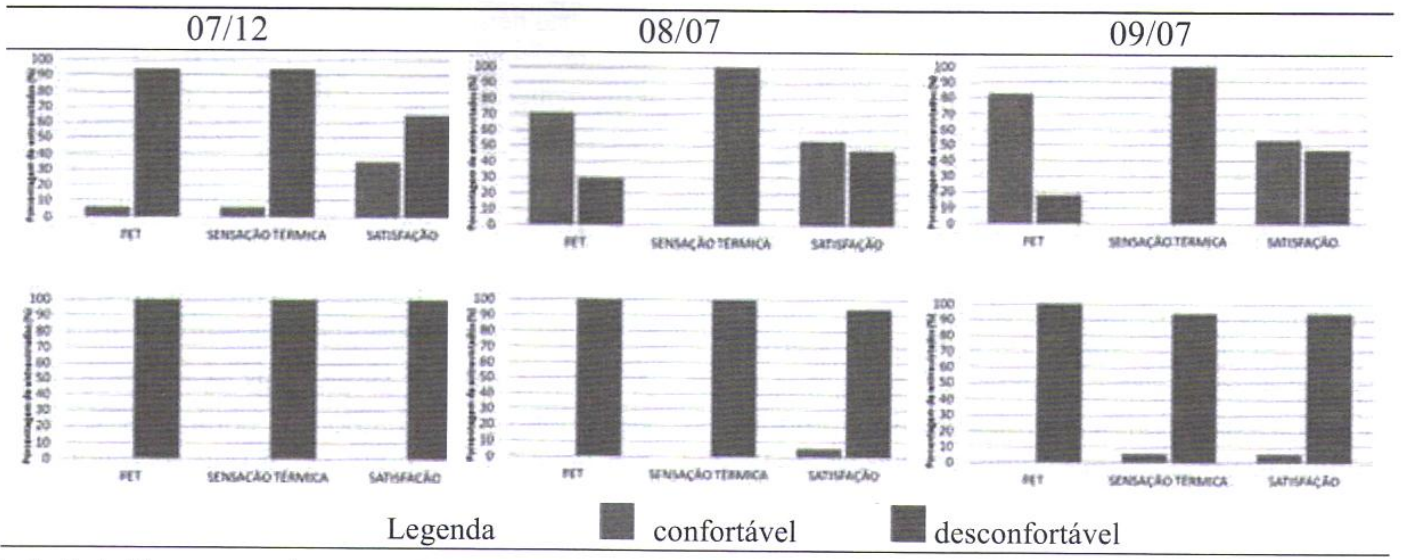

Tabela 4: Análise comparativa por períodos (manhã e tarde) entre o conforto térmico real (sensação térmica), conforto térmico calculado (PET) e satisfação térmica, nos dias 7, 8 e 9 de dezembro de 2010.

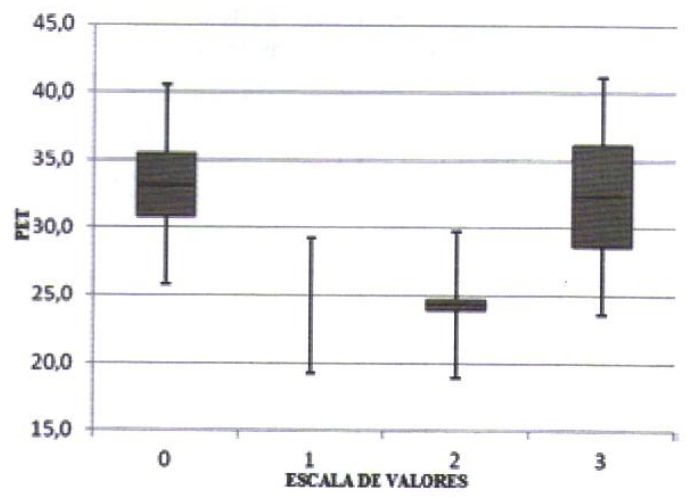

\begin{tabular}{l|c|c|c}
\hline \multirow{2}{*}{ Escala de valores } & \multicolumn{3}{|c}{ Faixa de PET para 50\% } \\
& \multicolumn{2}{|c|}{ dos valores centrais $\left({ }^{\circ} \mathrm{C}\right)$} \\
\cline { 2 - 4 } & Mín & Med & Max \\
\hline $\begin{array}{l}\text { Nem frio nem } \\
\text { quente (0) }\end{array}$ & 30,8 & 33,2 & 35,5 \\
\hline Pouco quente (1) & 24,2 & 24,2 & 24,2 \\
\hline Quente (2) & 23,9 & 24,3 & 25,9 \\
\hline Muito quente (3) & 28,6 & 32,4 & 35,3 \\
\hline
\end{tabular}

Figura 5: Gráfico tipo Box plot com distribuição do conjunto de valores de PET para cada voto de sensação térmica e tabela com as medianas (med) e dos limites (mínimo e máximo) de conforto/desconforto para $50 \%$ dos valores centrais durante os dias 6,7 e $8 / 12 / 2010$ 
A análise comparativa entre o conforto térmico -eal (sensação térmica) e calculado (pelo índice गET), além da satisfação térmica, pode ser visualizada na tabela 4 . Nesse período, apenas $2 \%$ das 101 pessoas entrevistadas disseram sentir nem quente nem frio" para a sensação térmica, "esultado que representou uma quantidade sig-

- ficativa de pessoas desconfortáveis (98\%). As zausas do desconforto foram as altas temperauras, especialmente no período da tarde, além zas umidades relativas mais baixas nesse mesno período. Como se pode observar, as medijóes ocorridas no mês de dezembro revelaram - m período crítico do ano em virtude da grande nsatisfação térmica dos usuários, pois além do salor outros aspectos como o barulho e a falta ze qualidade do espaço urbano influenciaram negativamente a sensação de conforto térmico aos usuários.

A análise dos valores da PET para cada voto de

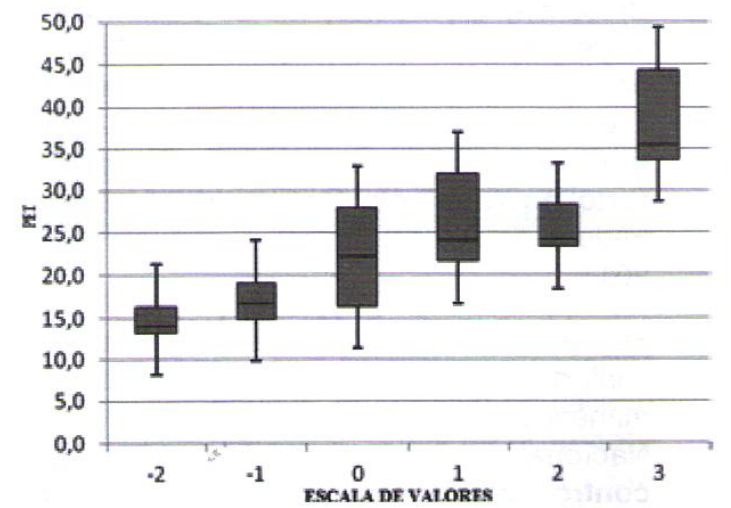

sensação (figura 5) evidenciou que o conjunto de dados foram distribuídos apenas nos valores "0, 1, 2 e 3". Contudo, a quantidade de pessoas que responderam "nem quente nem frio" e "pouco quente" foi insignificante, uma vez que juntas totalizaram apenas 3\% do total de entrevistados. Já as sensações térmicas correspondentes a "quente" e "muito quente" atingiram as porcentagens de 23,7 e $72,3 \%$, respectivamente, evidenciando uma maior dispersão de dados e de maior valor mediano para "-3", que representa grande desconforto térmico.

Para esse período, o aumento dos valores das medianas na escala de " 0,1 e 2", em relação ao período anterior, mostra um indício das variações dos limites de conforto com as estações do ano. Entretanto, para concretizar essa afirmação seria necessário a existência de valores mais significativos.

\subsection{Análise Cojunta dos Resultados}

\begin{tabular}{|c|c|c|c|}
\hline \multirow[t]{2}{*}{ Escala de valores } & \multicolumn{3}{|c|}{$\begin{array}{l}\text { Faixa de PET para } 50 \% \\
\text { dos valores centrais }\left({ }^{\circ} \mathrm{C}\right)\end{array}$} \\
\hline & Mín & Med & Max \\
\hline Frio & 13,3 & 14,1 & 21,1 \\
\hline Pouco Frio & 14,8 & 16,7 & 19,1 \\
\hline $\begin{array}{l}\text { Nem frio nem } \\
\text { quente }\end{array}$ & 16,4 & 22,2 & 28,0 \\
\hline Pouco quente (1) & 21,7 & 24,0 & 32,0 \\
\hline Quente & 23,4 & 24,3 & 28,4 \\
\hline Muito quente (3) & 33,7 & 35,4 & 44,3 \\
\hline
\end{tabular}

Figura 6: Gráfico tipo Box plot com distribuição do conjunto de valores de PET para cada voto de sensação térmica e tabela com as medianas (med) e dos limites (mínimo e máximo) de conforto/desconforto para $50 \%$ dos valores centrais nos dois períodos analisados

A análise conjunta dos dois períodos (julho e dezembro) é realizada através da figura 6 , que apresenta a distribuição de todos os valores encontrados para o índice PET para cada voto de sensação. Observa-se no gráfico que não existe valores destoantes dos demais (outliers), e uma ordem crescente nos valores medianos para cada voto de sensação, com valor mínimo de 14,1 oC para "-2"e máximo de 35,4 oC para " 3 ". Para a faixa de conforto térmico ("0") o valor mediano foi de 22,2 oC, e os valores mínimo e máximo foram de 16,4 e $280 C$, respectivamente. Entretanto, verifica-se uma sobreposição dessa faixa com alguns valores que indicam stress térmico por frio ou calor, o que mostra a capacidade adaptativa dos usuários, ao mesmo tempo que demonstra a dificuldade da definição precisa de cada faixa. Apenas a faixa de 33,7 a $44,30 C$, correspondente ao stress por muito calor se encon- tra totalmente definida, isto é, sem sobreposição das demais.

Comparando a faixa de conforto de 16,4 e 28 oC, encontrada nesse estudo, com a de 21 a $30^{\circ} \mathrm{C}$ desterminada em outro similar realizado em uma rua de pedestres em Bauru, citado por Labaki et. al. (2012), verifica-se uma maior amplitude nos limites de conforto. Entretanto, os valores medianos de ambos estudos foram similares, em torno de 22 oC. Outro aspecto semelhante nos dois estudos foi a maior tolerância às temperaturas baixas e intolerância às altas. Esses resultados contrastam com os obtidos em espaços públicos de permanência arborizados, cujos limites máximos para a neutralidade térmica são mais amplos como apresentados por Fontes et al. (2010), evidenciando maior tolerância as altas temperaturas. 


\section{Conclusão}

Os resultados obtidos nesta pesquisa contribuem para os estudos brasileiros que buscam determinar os limites de conforto térmico em espaços abertos. Para o caso específico da cidade de Bauru, o trabalho corrobora com outras pesquisas concluídas e em andamento em espaços de passagem (ruas e avenidas) e de permanência (praças), objetivando a calibração das faixas de conforto e desconforto para o índice PET nesses dois tipos de espaços. Outra contribuição da pesquisa diz respeito a sua utilidade na avaliação da qualidade térmica de um importante corredor urbano de Bauru, cidade regional do Estado de São Paulo, necessária para subsidiar projeto de requalificação urbana.

A pesquisa, realizada com 202 usuários de uma avenida de grande movimentação, evidenciou uma faixa de conforto térmico para o índice PET entre 16,4 e 28 oC. Essa faixa é mais ampla do que a observada em estudo similar realizado em Bauru $\left(21\right.$ a $\left.30{ }^{\circ} \mathrm{C}\right)$, em uma rua de pedestres próxima, citado em Labaki et. al. (2012). Além disso, a pesquisa também identificou que as condições de tempo quente são as mais críticas para os usuários, uma vez que foi observado uma grande porcentagem de pessoas desconfortáveis, tanto através de votos subjetivos como objetivamente, a partir do cálculo do índice PET. Os baixos valores da umidade relativa do ar, observados durante as tardes nos dois períodos, também afetaram significativamente as condições de conforto dos usuários.

A comparação desse estudo com outro desenvolvido em um espaço público de permanência arborizado em Bauru (Brusantin \& Fontes, 2011; Fontes et al., 2010) ressaltou diferenças entre as faixas de conforto térmico nesses dois tipos de espaços. Em espaços de permanência arborizados as condições de tempo frio encontradas foram mais agravantes para o conforto térmico dos usuários e a tolerância as altas temperaturas foi maior, mesmo em condições adversas. Ao contrário desses espaços, o espaço de passagem analisado apresentou uma maior tolerância às temperaturas mais baixas e menor as mais altas.

A partir desses resultados, são sugeridas outras pesquisas similares em Bauru e em outras cidades brasileiras, objetivando identificar as principais diferenças entre as faixas de conforto e desconforto térmico em tipologias diferenciadas de espaços públicos de passagem (ruas, avenidas e espaços lineares para recreação e circulação de pedestres e bicicletas) e de per- manência (praças e parques). É importante verificar, ainda, se os diferentes tipos de espaços de passagem possuem comportamento similar, ou se algum deles se comporta como espaços de permanência, como por exemplo os espaços lineares projetados para recreação e circulação de pedestres e bicicletas.

\section{Agradecimentos}

Os autores agradecem a agência de fomento FAPESP (Fundação de Amparo a Pesquisa do Estado de São Paulo) pelo apoio financeiro a esta pesquisa e ao IPMet pelo fornecimento de dados climáticos de Bauru.

\section{Referências}

Centro de Pesquisas Meteorológicas e climáticas aplicadas a agricultura - CEPAGRI -. Clima dos municípios paulistas (internet) Disponível em ahttp://www.cpa.unicamp.bra. (Consult, 10 de janeiro 2011).

Brusantin, G., Fontes, M. S. Conforto térmico em espaços públicos de permanência: uma experiência na cidade de Bauru, SP, Anais do XI Encontro Nacional de Conforto no Ambiente e VII Encontro Latino-Americano sobre conforto no Ambiente Construído. Universidade Federal do Rio de Janeiro, Brasil, 17-19 agosto 2011.

Fontes, M. S. G. de C., Brusantin, G. Limites de conforto térmico em um espaço público de permanência arborizado, Anais do XI Encontro Nacional de Conforto no Ambiente e VII Encontro Latino-Americano sobre conforto no Ambiente Construído. Universidade Federal do Rio de Janeiro, Brasil, 17-19 agosto 2011.

Fontes, M. S. G. de C., Dacanal, C, Bueno-Bartholomei, Nikolopoulou, M., Labaki, L C., Thermal Comfort in Open Public Spaces: studies in green areas in cities of the Sao Paulo State, Brazil, Proceedings 3rd International Conference on Passive and Low Energy Cooling for the Built Environment, University of Athens, Greece, 21 set- 1 out, 2010.

Hirashima, S. Q. da S., Assis, E. S. de, Ferreira, D. G. Calibração do índice de conforto térmico Temperatura Fisiolçogica Equivalente (PET) para espaços abertos do Município de Belo Horizonte-MG, Anais do XI Encontro Nacional de Conforto no Ambiente e VII Encontro Latino-Americano sobre conforto no Ambiente Construído. Universidade Federal do Rio de Janeiro, Brasil, 17-19 agosto 2011.

Höppe, P. (1993). Heat Balance Modelling. Experientia, Basel, 9 (49), 741-746. 
Höppe, P. (1999). The Physiological Equivalent Temperature: a universal index for the biometeorological assessment of the thermal environment, International Journal of Biometeorology, Lisse, 2 (43), 71-75.

Krüger, E.L., Drach, P. R. C., Emmanuel, R., Corbella (2012). Estudo de conforto em espaços abertos em região de clima temperado: o caso de Glasgow, Reino Unido, Ambiente Construído, 1(12), 7-25.

Labaki, L C., Fontes, M. S. G., Bueno-Bartolomei, C. L, Dacanal, C. Conforto térmico em espaços públicos de passagem: estudos em ruas de pedestres no Estado de São Paulo, Ambiente Construído, 1(12), 167-183.

Matzarakis, A, Rutz, F., Mayer, H. (2007) Modelling radiation Fluxes in Simple and Complex Environments: application of the RayMan model, International Journal of Biometeorology (51) .323-334.

Mayer, H.; Höppe, P (1987). Thermal Comfort of Man in Different Urban environments, Theoretical and Applied Climatology, (38), 43-49.

Monteiro, L. M., Alucci, M. P. Modelo adaptativo de conforto para avaliação in loco de espaços urbanos abertos, Ambiente Construído, 1(12), $61-79$

Monteiro, L. M.; Alucci, M. P. Conforto Térmico em Espaços Abertos com diferentes brangências Microclimáticas: parte 2: proposição de calibração de modelos preditivos, Anais do IX Encontro Nacional de Conforto no Ambiente e V Encontro Latino- Americano sobre conforto no Ambiente Construído. Universidade Federal do Rio de Janeiro, Brasil, 8-10 agosto 2007.

Rancura, R., Labaki, L. C. Conforto térmico em espaços externos: feiras livres em Indaiatuba, Anais do XI Encontro Nacional de Conforto no Ambiente e VII Encontro Latino-Americano sobre conforto no Ambiente Construído. Universidade Federal do Rio de Janeiro, Brasil, 17-19 agosto 2011

Romero, M. A. B (1988). Princípios bioclimáticos para o desenho Urbano. Projeto, São Pau10 .

Rossi, F. A., Krüger, E.L., Bröde (2012). Definição de faixas de conforto térmico para espaços abertos em Curitiba, PR, com o índice UTCI, Ambiente Construído, 1(12), 41- 59.

Rossi, F. A., Krüger, E.L., Nikolopoulou (2011). A influência da configuração urbana no microclima e na sensação térmica em ruas de pedestres de Curitiba, Paraná, Anais do XI Encontro Nacio- nal de Conforto no Ambiente e VII Encontro Latino-Americano sobre conforto no Ambiente Construído. Universidade Federal do Rio de Janeiro, Brasil, 17-19 agosto 2011.

Shimakawa, A. H., Bueno-Bartholomei, C. L. Praça nove de julho: o conforto térmico em espaços públicos abertos na cidade de Presidente Prudente - SP, Anais do XI Encontro Nacional de Conforto no Ambiente e VII Encontro Latino-Americano sobre conforto no Ambiente Construído. Universidade Federal do Rio de Janeiro, Brasil, 17-19 agosto 2011.

Wolfram, B. R., Monteiro, L. M. Avaliação da influência da arborização no conforto térmico do pedestre em meio urbano: estudo de caso espaços abertos do Bairro da Luz, São Paulo, SP, Anais do XI Encontro Nacional de Conforto no Ambiente e VII Encontro Latino-Americano sobre conforto no Ambiente Construído. Universidade Federal do Rio de Janeiro, Brasil, 7-19 agosto 2011. 